\title{
Inertial currents in the Indian Ocean derived from satellite tracked surface drifters
}

\author{
P. Kuttan SAJI *, Satheesh C. SHENOI, Anselm ALMEIDA, Gangadhara RAO \\ National Institute of Oceanography, Dona-Paula, Goa 403 004, India
}

Received 10 September 1999; revised 20 March 2000; accepted 5 April 2000

\begin{abstract}
Satellite-tracked surface drifters were used to analyze the characteristics of inertial currents in the tropical Indian Ocean. The drifters were drogued at $15 \mathrm{~m}$ depth and had wind-produced slips less than $0.1 \%$ of the wind speed. The rotary spectra of surface velocity components indicated the significance of inertial currents. They are circular (rotary coefficient $>0.5$ ), highly intermittent and contribute up to $46 \%$ to the total kinetic energy of the surface flow field. Events of inertial activity, either triggered by the passage of atmospheric disturbances or by the local fluctuations in the atmospheric pressure (winds), did not last for more than 4 to 5 inertial cycles. The observed inertial frequency exhibited a shift towards the red end of the spectrum by $12 \%$. Cyclonic storm induced inertial events even at a location $300 \mathrm{~km}$ away from it. (C) $2000 \mathrm{Ifremer} / \mathrm{CNRS} / \mathrm{IRD} / \mathrm{E} d i-$ tions scientifiques et médicales Elsevier SAS
\end{abstract}

Résumé - Courants d'inertie dans l'océan Indien estimés à partir de flotteurs de surface suivis par satellite. Des flotteurs de surface suivis par satellite ont été utilisés pour analyser les caractéristiques des courants d'inertie dans l'océan Indien tropical. Largués à 15 mètres de profondeur, ces flotteurs présentent une vitesse de dérive inférieure à $0,1 \%$ de celle du vent. Le spectre de rotation des composantes de la vitesse superficielle souligne l'importance des courants d'inertie. Ceux-ci sont circulaires (coefficient de rotation $>0.5$ ), très intermittents et ils contribuent environ à $46 \%$ de l'énergie cinétique totale du champ de courants superficiels. Les événements de l'activité inertielle, qu'ils soient provoqués par le passage de perturbations atmosphériques ou par des fluctuations locales de pression atmosphérique (vents), ne durent pas plus de 4 à 5 cycles d'inertie. La fréquence d'inertie observée est déplacée vers les basses fréquences du spectre d'environ $12 \%$. Un cyclone génère des événements inertiels jusqu'à 300 kilomètres du lieu où il se situe. C 2000 Ifremer/CNRS/IRD/Éditions scientifiques et médicales Elsevier SAS

\section{Inertial current / drifting buoy / Indian Ocean}

Courant d'inertie / flotteurs de surface / océan Indien

\section{INTRODUCTION}

Inertial currents in the ocean rotate clockwise (anticlockwise) in the northern (southern) hemisphere with period $T=2 \pi / 2 \Omega \sin \theta$; where $\Omega$ is the angular velocity of earth and $\theta$ the local latitude of observation (Perkins, 1972). The inertial currents were ob-

\footnotetext{
* Correspondence and reprints:

E-mail address: pksaji@csnio.ren.nic.in (P.K. Saji).
}

served in the oceans and large lakes at all depths with velocities ranging from $10-80 \mathrm{~cm} \cdot \mathrm{s}^{-1}$ (Webster, 1968) and are believed to be forced primarily by the winds (Pollard, 1970; Poulain, 1990). It has been estimated that the energy in the inertial band can account for more than $50 \%$ (Pollard, 1980; Thomson et al., 1998) of the total kinetic energy present in the mixed layer. Due to the substantial contribution of energy from the inertial oscillations, it would be worthwhile to document the inertial currents in greater detail in every ocean basin. 
Table I. Mean latitude, mean inertial frequency and the variation in the inertial frequency due to the meridional excursions of the individual buoys within a selected latitude band.

\begin{tabular}{|c|c|c|c|c|}
\hline Latitude band & Buoy ID & Mean latitude & $\begin{array}{l}\text { Mean inertial } \\
\text { frequency (cpd) }\end{array}$ & $\begin{array}{l}\text { Variance of inertial } \\
\text { frequency }(\mathrm{cpd})\end{array}$ \\
\hline $05-10 \mathrm{~N}$ & 02288 & 7.106 & 0.247 & 0.002 \\
\hline $05-10 \mathrm{~N}$ & 04852 & 8.203 & 0.285 & 0.001 \\
\hline $05-10 \mathrm{~S}$ & 04865 & 8.028 & 0.279 & 0.001 \\
\hline $05-10 \mathrm{~S}$ & 04866 & 6.296 & 0.219 & 0.000 \\
\hline $05-10 \mathrm{~N}$ & 04868 & 8.884 & 0.309 & 0.001 \\
\hline $05-10 \mathrm{~N}$ & 09081 & 6.324 & 0.220 & 0.002 \\
\hline $05-10 \mathrm{~N}$ & 09080 & 8.253 & 0.287 & 0.001 \\
\hline $05-10 \mathrm{~N}$ & 15705 & 8.096 & 0.282 & 0.000 \\
\hline $10-15 \mathrm{~N}$ & 15705 & 12.663 & 0.438 & 0.002 \\
\hline $10-15 \mathrm{~S}$ & 11353 & 12.706 & 0.440 & 0.002 \\
\hline $10-15 \mathrm{~S}$ & 11352 & 11.885 & 0.412 & 0.002 \\
\hline $10-15 \mathrm{~N}$ & 15702 & 12.065 & 0.418 & 0.001 \\
\hline $10-15 \mathrm{~N}$ & 15708 & 13.978 & 0.483 & 0.000 \\
\hline $10-15 \mathrm{~N}$ & 11353 & 12.542 & 0.434 & 0.002 \\
\hline $10-15 \mathrm{~N}$ & 11355 & 12.119 & 0.420 & 0.002 \\
\hline $10-15 \mathrm{~S}$ & 06131 & 13.148 & 0.455 & 0.000 \\
\hline $10-15 \mathrm{~S}$ & 21140 & 12.950 & 0.448 & 0.002 \\
\hline $10-15 \mathrm{~N}$ & 21843 & 11.509 & 0.399 & 0.001 \\
\hline $10-15 \mathrm{~N}$ & 21854 & 12.716 & 0.440 & 0.002 \\
\hline $10-15 \mathrm{~S}$ & 21860 & 12.572 & 0.435 & 0.003 \\
\hline $10-15 \mathrm{~S}$ & 21900 & 13.053 & 0.452 & 0.002 \\
\hline $10-15 \mathrm{~S}$ & 21903 & 12.030 & 0.417 & 0.002 \\
\hline $10-15 \mathrm{~S}$ & 21926 & 12.757 & 0.442 & 0.002 \\
\hline $10-15 \mathrm{~S}$ & 21927 & 12.482 & 0.432 & 0.001 \\
\hline $10-15 \mathrm{~S}$ & 21929 & 12.895 & 0.446 & 0.002 \\
\hline $10-15 \mathrm{~S}$ & 21933 & 11.896 & 0.412 & 0.003 \\
\hline $10-15 \mathrm{~S}$ & 21952 & 10.481 & 0.364 & 0.000 \\
\hline $10-15 \mathrm{~S}$ & 23462 & 13.806 & 0.477 & 0.002 \\
\hline $10-15 \mathrm{~N}$ & 25829 & 11.106 & 0.385 & 0.001 \\
\hline
\end{tabular}

Traditionally, the time series of currents obtained through moored instruments were used for the analysis of inertial and high frequency motions. Of late, the semi-lagrangian satellite-tracked surface drifters are also being used to analyze the high frequency motions (D'Asaro, 1985; Poulain, 1990; Poulain et al., 1992; Thomson et al., 1998). The use of drifters for the analysis of inertial currents are advantageous as the drifter trajectories reproduce the inertial current loops.

Very few observations exists on the inertial currents in the Indian ocean. Though there are few from Arabian sea (Rao et al., 1996; Shenoi and Antony, 1991), there are none from the Bay of Bengal and other regions of the tropical Indian ocean. This note presents the characteristics of inertial currents in the near surface layer of the tropical Indian ocean, their spectral characteristics and the response to the atmospheric forcings.

\section{MATERIALS AND METHODS}

The data from 29 drifting buoys, extracted from the archives of Atlantic Oceanographic and Meteorological Laboratory (AOML), National Institute of Oceanography (NIO) (Shenoi et al., 1997) and the data personally obtained from Dr Robert Molinari are used in this analysis. All the drifters had a $7 \mathrm{~m}$ long holey-sock drogue centered at a nominal depth of $15 \mathrm{~m}$ to ensure the water particle following property of the drifter and a drogue ON/OFF sensor to continuously monitor its presence. The data are included in this analysis only when the buoy had the drogue. The buoy with a drag area ratio, $R$, greater than 37 is expected to have a downwind slip less than $0.1 \%$ of the wind speed (Niiler et al., 1995); hence, only those buoys were included in this analysis. Even with a wind speeds of $15 \mathrm{~m} \cdot \mathrm{s}^{-1}$ the error introduced 


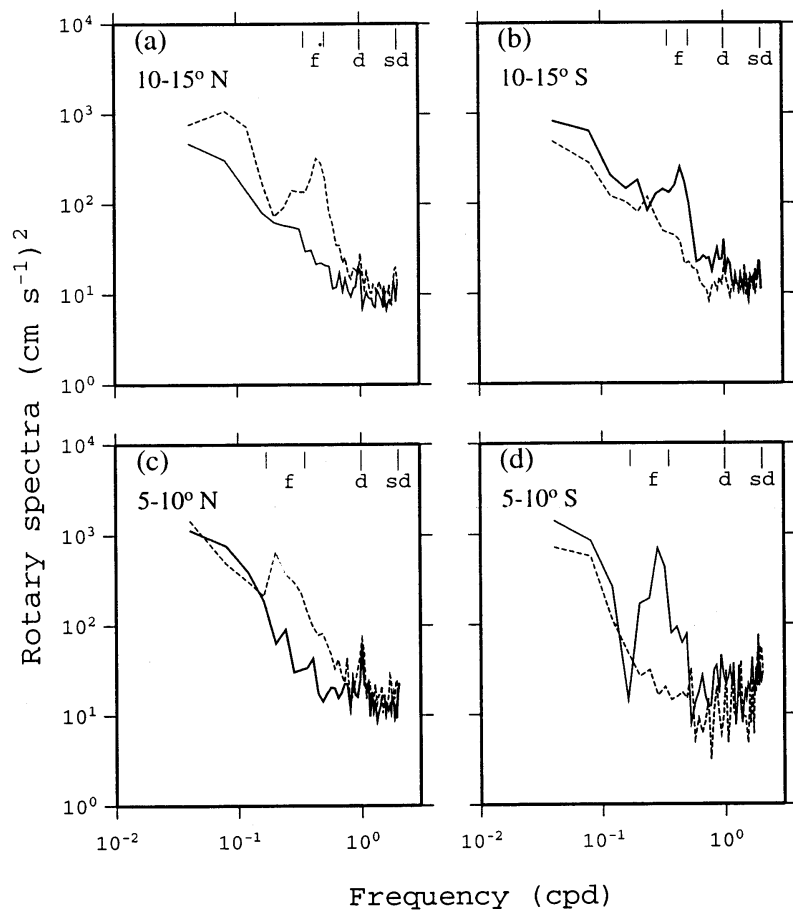

Figure 1. Average rotary spectra of the currents from latitude bands (a) $10-15^{\circ} \mathrm{N}$, (b) $10-15^{\circ} \mathrm{S}$, (c) $5-10^{\circ} \mathrm{N}$ and (d) $5-10^{\circ} \mathrm{S}$. The inertial, diurnal and semi-diurnal frequencies are marked with "f", "d" and "sd" respectively. Dashed (solid) line represents the clockwise (anticlockwise) rotation.

by the winds due to the slip of the drogue will not exceed $1.5 \mathrm{~cm} \cdot \mathrm{s}^{-1}$ (Shenoi et al., 1999), which is very small compared to the typical inertial current amplitude $\left(\sim 15 \mathrm{~cm} \cdot \mathrm{s}^{-1}\right)$. However, during the passage of storms the error introduced by the downwind slips could reach $6 \mathrm{~cm} \cdot \mathrm{s}^{-1}$. In this analysis, however, we have not corrected the data for the downwind slips.

Satellite based Argos system was used to determine the position of the buoy to an accuracy of approximately $350 \mathrm{~m}$ (Anonymous, 1990). The unevenly spaced time series of buoy positions (up to 8 per day) were checked for consistency and edited to remove the dubious positions (Hansen and Poulain, 1996). It is then interpolated using splines, to generate 4 equally-spaced values a day, and were used to construct the time series of zonal $(u)$ and meridional $(v)$ velocities.

The buoys moved in the latitude bands $5-10^{\circ} \mathrm{N}$ and $\mathrm{S}$ and $10-15^{\circ} \mathrm{N}$ and $\mathrm{S}$ were selected for the analysis only if they remained within the specified latitudinal bands for a period of 50 days or more. The drifters moved within a latitude band showed limited meridional excursions and hence negligible variations in the inertial frequency (see table I).

\section{RESULTS}

\subsection{Spectral characteristics}

In order to determine the distribution of the kinetic energy due to horizontal currents as a function of frequency of motion, the average rotary spectra were determined for each latitude band following Gonella (1972). The significant peaks of velocity spectra in the inertial band indicate the substantial presence of inertial currents in the tropical Indian Ocean (figure 1). The energy in the inertial band is well above the tidal and higher frequency oscillations. As expected, the

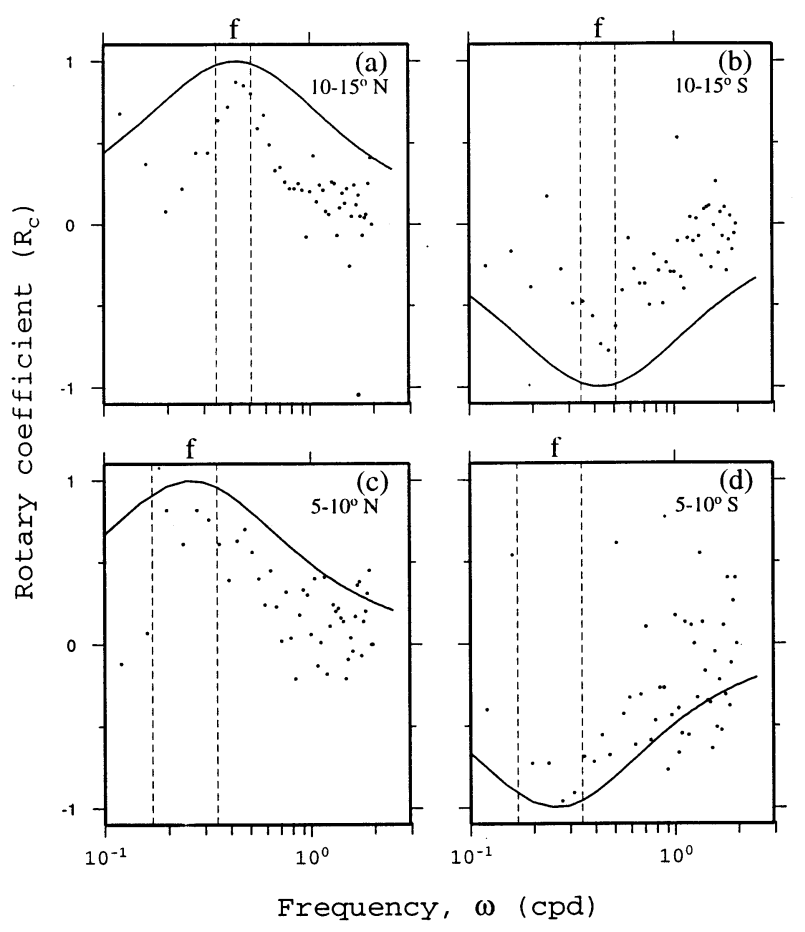

Figure 2. Rotary coefficients estimated from the rotary spectra of the surface currents for latitude bands (a) $10-15^{\circ} \mathrm{N}$, (b) $10-15^{\circ} \mathrm{S}$, (c) $5-10^{\circ} \mathrm{N}$ and (d) $5-10^{\circ} \mathrm{S}$. The solid line represents the theoretical rotary coefficient $R_{\mathrm{t}}=2 \omega f /\left(\omega^{2}+f^{2}\right)$, where $f$ is the Coriolis frequency for the mean latitude and $\omega$ is the frequency of motion. Inertial frequency band is marked with " $f$ ". 


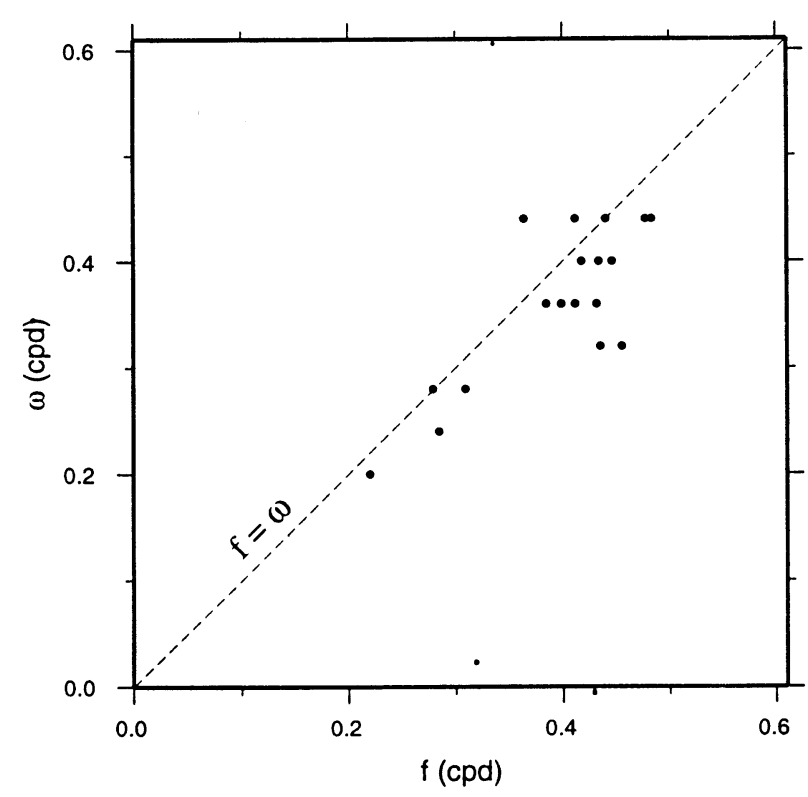

Figure 3. Scatter plot of theoretical $(f)$ vs. observed $(\omega)$ inertial frequencies.
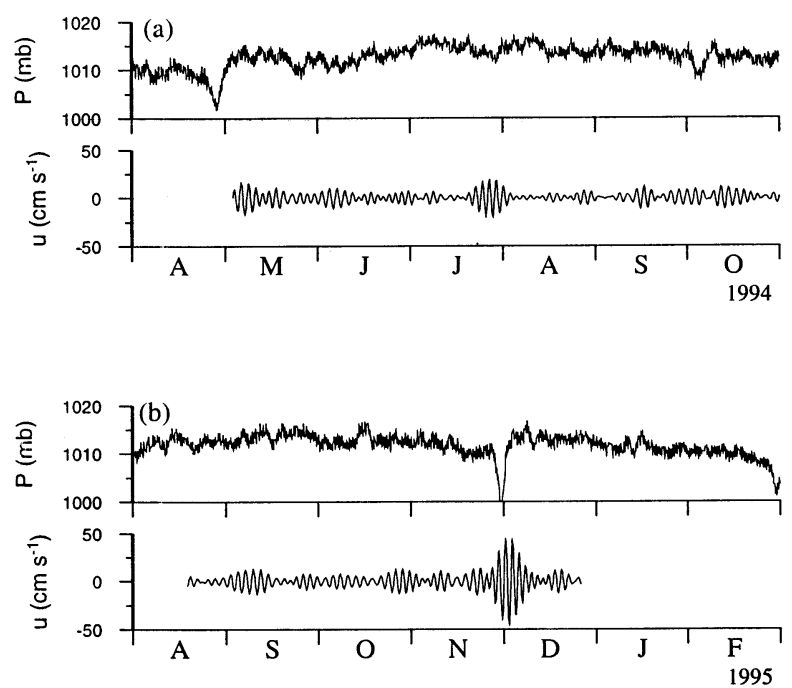

Figure 4. Zonal component $(u)$ of inertial current and atmospheric pressure from buoys (a) 11352 and (b) 11353. A band pass filter in time domain was used for the extraction of inertial currents.

inertial current in the northern bands rotated clockwise while that in the southern band rotated anticlockwise. In both the hemispheres, the energy within the inertial band for the $5-10^{\circ}$ latitude band appears to be higher than the inertial energy in the $10-15^{\circ}$ band.
The rotary coefficients $\left(\mathrm{R}_{\mathrm{c}}\right)$, which indicate the strength and sense of the rotary motion are estimated as

$\mathrm{R}_{\mathrm{c}}=\left(\mathrm{S}_{-}-\mathrm{S}_{+}\right) /\left(\mathrm{S}_{-}+\mathrm{S}_{+}\right)$

where $\mathrm{S}_{-}$and $\mathrm{S}_{+}$are the clockwise and anticlockwise spectra respectively (Gonella, 1972). For currents rotating in a perfect circle, the magnitude of $R_{c}$ is unity and for rectilinear motion it is zero. In the inertial band, for most of the buoys, $\mathrm{R}_{\mathrm{c}}$ varies be-
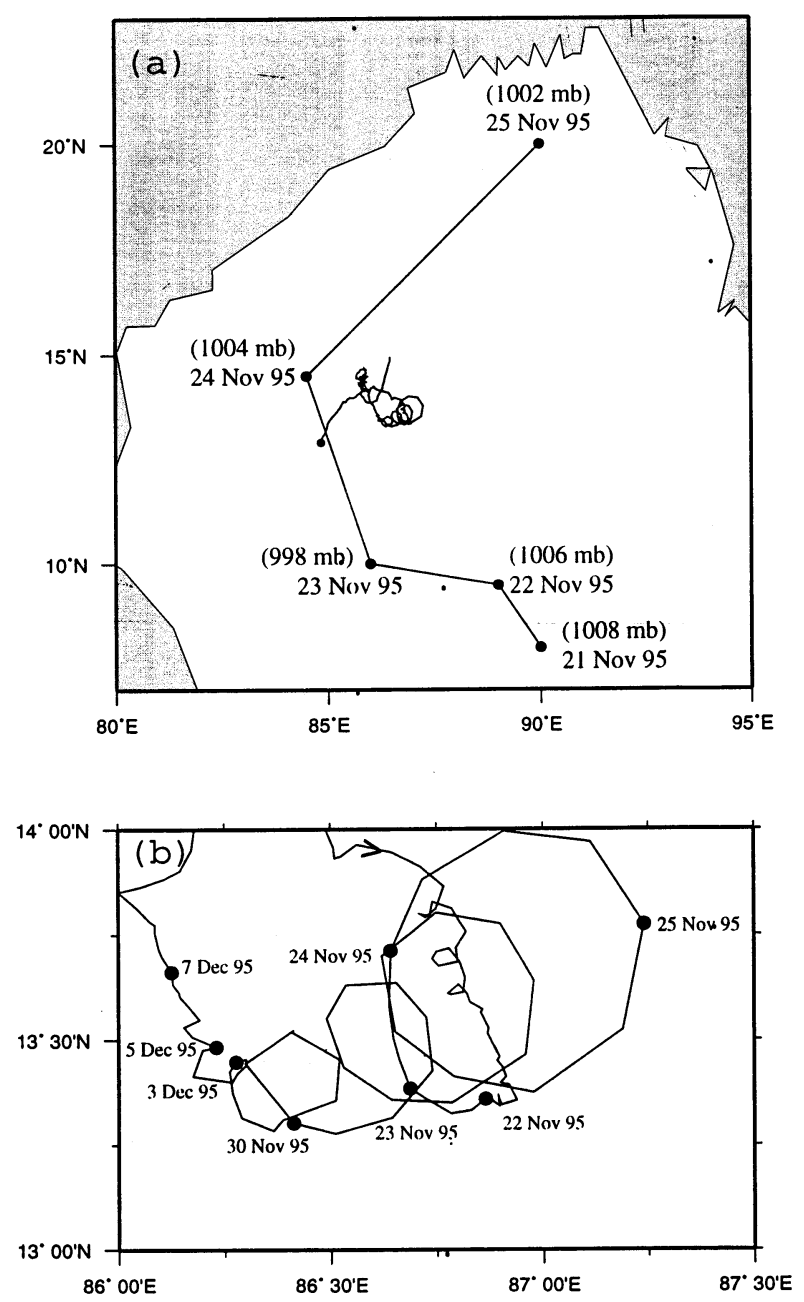

Figure 5. (a) Trajectory of the buoy during the passage of a cyclone over the Bay of Bengal. The Indian Daily Weather Report published by India Meteorological Department, New Delhi for the period 22-25 November 1995 was used to construct the track of the cyclone. The numbers in parenthesis above the dates note the mean sea level pressure. (b) The enlarged view of the buoy trajectory. 
tween 0.5 to 0.98 (figure 2). At the inertial frequency, values of $R_{c}$ are lower than the theoretical values estimated following (Fofonoff, 1969). This indicates greater rectilinearity of the observed inertial motions.

As indicated in table I, the buoys selected in this analysis have minimal meridional excursions and hence have negligible variations in the inertial frequencies associated with the change in latitudes. Earlier studies (Poulain, 1990; Salat et al., 1992; Thomson et al., 1998) report a shift between the observed and theoretical inertial frequencies. To estimate such shifts, the inertial frequency corresponding to the mean latitude around which the buoy moved, is considered as the theoretical frequency (f) and the frequency corresponding to the peak in the rotary spectra in the inertial band is considered as the observed inertial frequency $(\omega)$. Out of the 19 buoys used to compute the frequency shift (figure 3), 16 showed red shift (i.e. observed inertial frequency less than the theoretical frequency) and the remaining 3 showed blue shift (i.e. observed frequency greater than the theoretical frequency). The average red and blue shifts work out to be $12 \%$ and $5 \%$, respectively. Poulain (1990) reported a red shift of $0.07 \mathrm{cpd}$ in the observed inertial frequency for the observations from North Pacific (California Current System). Likewise, Thomson et al. (1998) have reported a blue shift of $1.3 \%$ in the northeast Pacific, and Salat et al. (1992) reported a red shift of $10 \%$ in the shelf-slope front off northeast Spain. Interaction with the background mesoscale circulation is believed to be responsible for the shift of observed frequency towards the red side of the spectrum (Poulain, 1990).

\subsection{Intermittence of inertial currents}

The inertial currents in the Indian ocean exhibited large temporal and spatial variations. Their magnitudes often varied from $10 \mathrm{~cm} \cdot \mathrm{s}^{-1}$ to $75 \mathrm{~cm} \cdot \mathrm{s}^{-1}$ and intensified only for a short duration. Mostly, the intensification continued for about 4 to 5 cycles (i.e., 14 to 28 days at $5-10^{\circ}$ latitude band and 9 to 14 days at $10-15^{\circ}$ band). The average contribution of the inertial currents to the surface currents is $36 \%$ for $10-15^{\circ}$ latitude band and $46 \%$ for $5-10^{\circ}$ band.

The local fluctuations in the atmospheric pressure/local winds always precedes the intensification in the inertial currents (figure 4). Such responses are more prominent, during the passages of cyclonic storms. Figure 5 accounts one such instance where a cyclonic storm passed over the Bay of Bengal during 21 to 25 November 1995 and intensified the inertial currents at a location as far as $300 \mathrm{~km}$ away from it. With the growth of the storm (a low on 21st, deep depression on 22nd and severe cyclone on 23 November 1995) the magnitude of the inertial currents as well as the size of the inertial loops $(66 \mathrm{~km}$ wide on 25 November 1995) grew almost simultaneously. The inertial current attained a maximum speed of $75 \mathrm{~cm} \cdot \mathrm{s}^{-1}$ on 25 November during this process. This event, though strong, also didn't last for more than 5 inertial cycles (i.e. 11 days).

\section{Acknowledgements}

The authors would like to thank the Global Drifter Centre at AOML, Miami and Dr Robert Molinari for providing the drifter data from their archives. This work was supported by the grants from Department of Ocean Development, New Delhi. The graphics package GMT was used extensively. Comments from the anonymous referees helped in improving the manuscript. This is NIO contribution 3546 .

\section{REFERENCES}

Anonymous, 1990. ARGOS User manual, Chapter 3, 29-31.

D'Asaro, E.A., 1985. Upper ocean temperature structure, inertial currents and Richardson numbers observed during strong meteorological forcing. J. Phys. Oceanogr. 15, 943-962.

Fofonoff, N.P., 1969. Spectral characteristics of internal waves in the ocean. Deep Sea Res. 16, 59-71.

Gonella, J., 1972. A rotary component method for analysing meteorological and oceanographic vector time series. Deep Sea Res. 19, 833-846.

Hansen, D.V., Poulain, P.M., 1996. Processing of WOCE/TOGA drifter data. J. Atm. Ocean. Tech. 13, 900-909.

Niiler, P.P., Sybrandy, A.S., Bi, K., Poulain, P.M., Bitterman, D., 1995. Measurements of the water-following characteristics of Tristar and Holeysock drifters. Deep Sea Res. 42, 1951-1964.

Perkins, H., 1972. Inertial oscillations in the Mediterranean. Deep Sea Res. 19, 289-296.

Pollard, R.T., 1970. On the generation by winds of inertial waves in the ocean. Deep Sea Res. 17, 795-812. 
Pollard, R.T., 1980. Properties of near-surface inertial oscillations. J. Phys. Oceanogr. 10, 385-398.

Poulain, P.M., 1990. Near-inertial and diurnal motions in the trajectories of mixed layer drifters. J. Mar. Res. 48, 793-823.

Poulain, P.M., Luther, D.S., Patzert, W.C., 1992. Deriving inertial wave characteristics from surface drifter velocities: Frequency variability in the tropical Pacific. J. Geophys. Res. 97, 1794717959.

Rao, R.R., Kumar, K.V.S., Mathew, B., 1996. Observed variability in the current field during summer monsoon experiments: Arabian Sea. Mausam 47, 355-368.

Salat, J., Tintore, J., Font, J., Wang, D., Vieira, M., 1992. Near-inertial motion on the shelf-slope front off Northeast Spain. J. Geophys. Res. 97, 7277-7281.
Shenoi, S.C., Antony, M.K., 1991. Current measurements over the western continental shelf of India. Con. Shelf Res. 11, 81-93.

Shenoi, S.C., Saji, P.K., Almeida, A.M., 1999. Near-surface circulation and kinetic energy in the tropical Indian Ocean derived from lagrangian drifters. J. Mar. Res. 57, 885-907.

Shenoi, S.C., Saji, P.K., Almeida A.M., Rama, Rao E.P., Michael, G.S., Nampoothiri, G., Rao, L.V.G., 1997. Drifter observations in Indian ocean, Techn. Rep. No. NIO/TR- 2/97.

Thomson, R.E., LeBlond, P.H., Rabinovich, A.B., 1998. Satellite-tracked drifter measurements of inertial and semidiurnal currents in the northeast Pacific. J. Geophys. Res. 103, 1039-1052.

Webster, F., 1968. Observations of inertial period motions in the deep sea. Rev. Geophys. 6, 473-490. 